
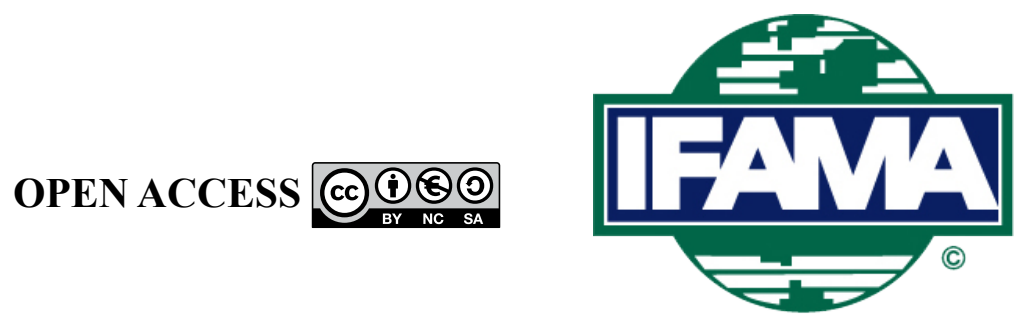

International Food and Agribusiness Management Review

Volume 25, Issue 2, 2022; DOI: 10.22434/IFAMR2020.0196

Received: 24 November 2020 / Accepted: 1 October 2021

\title{
Assessing the coordinated revenue-sharing contract of China's farmer-supermarket direct-purchase model
}

\section{RESEARCH ARTICLE}

\author{
Peng Liang ${ }^{\mathrm{a}}$, Melat Sima ${ }^{\mathrm{b}}$, Yu Huang ${ }^{\circledR \mathrm{c}}$ and Xiaoyu Sun ${ }^{\mathrm{b}}$ \\ ${ }^{a}$ Associate Professor, ${ }^{b}$ Researcher, School of Economics, Beijing Technology and Business \\ University, No. 33 Fucheng Road, Haidian District, Beijing, 100048, China P.R \\ ${ }^{c}$ Associate Professor, Institute of International and Comparative Education, Beijing Normal \\ University, No.19, Xinjiekouwai Street, Haidian District, Beijing, 100088, China P.R
}

\begin{abstract}
China began connecting farmers directly with supermarkets 10 years ago, when they were at a disadvantage and forced to sell products at low prices, as unstable cooperation among supply chain participants led to inequitable distribution of revenue. Revenue-sharing contracts offer a risk-sharing approach to ensure supply chain coordination and optimize profit for all. Research on short life cycle products with revenuesharing contracts assume stable prices or investigate the effects of revenue-sharing contracts on supply chain coordination. This study introduced a revenue-sharing contract model into a 'farmer-supermarket directpurchase' supply chain, considering price fluctuation and retail promotional efforts, stochastic market demand, among other factors. Revenue-sharing contracts achieved long-term stability in supply chain coordination, all participants obtained more profits, and the size of revenue-sharing parameter depends on the position and bargaining power of all participants. A case study on Tianhong supermarket and Nanxia farmer cooperative verified these findings, eliciting practical implications for professionals and policymakers.
\end{abstract}

Keywords: farmer-supermarket direct-purchase, perishable agricultural product, revenue-sharing contract, supply chain coordination

JEL code: Q13

\footnotetext{
${ }^{\circledR}$ Corresponding author: huangyu@bnu.edu.cn
} 


\section{Introduction}

The 'farmer-supermarket direct-purchase' model is a supply chain model for agricultural products in China in which farmers or farmers' cooperatives (suppliers) sign an agreement to sell agricultural products directly to supermarkets (retailers). This reduces excess intermediary links and brings costs down. The direct-purchase model helps supermarkets to establish a more stable, higher quality, more dependable, and more personalized supply source. It also creates an enabling environment for farmers, as they no longer must look for buyers, and can sell their products directly to supermarkets. This ensures a consistent market, presenting a triplewin among farmers, supermarkets, and consumers. With the support of Chinese national policies, and joint efforts of farmers and supermarkets, the direct-purchase model was developed to achieve outcomes such as stabilizing the market prices of agricultural products, raising the profits of participants in the supply chain, poverty reduction, and agricultural development in China (Ding and Gao, 2015; Hu and Yang, 2010; Ren et al., 2013). In recent years, large-scale pilot projects in China have applied the direct-purchase supply chain model, which has developed rapidly, gaining the recognition of an increasing number of farmers and supermarkets. However, the implementation of this model has not been smooth sailing. Numerous aspects of the model require further investigation and challenges remain to be solved.

Farmers are usually connected with supermarkets through third-party organizations, such as supply and marketing cooperatives, rather than through direct connection. This often leaves farmers at a disadvantage in the transaction process, with no choice but to sell products at lower prices, damaging farmers' profits and potentially causing less motivation to produce agricultural products. Unstable cooperation among supply chain participants also leads to the inequitable distribution of revenue. The establishment of a fair revenue distribution mechanism that benefits from direct, long-term cooperation between farmers and supermarkets under the farmer-supermarket direct-purchase model has received increasing attention from scholars. Studies have examined the revenue distribution of the agricultural products supply chain. Revenue-sharing contracts increase profits across an entire supply chain for all participants (Chauhan and Proth, 2004). Combined revenue-sharing with advance order discounts, such supply chain collaboration can ensure higher profits than the use of sole revenue-sharing or advance order discounts (Bellantuono et al., 2006). Suppliers can maximize the overall profit of a supply chain by providing incentives and price discounts for retailers (Jeuland and Shugan, 1983). Fairness in revenue distribution affects the decision-making behavior of vulnerable parties (Liu, 2011). Revenue- and cost-sharing can effectively coordinate a retailer-dominated supply chain while considering retailers' promotional ability (Liang and Fang, 2016). Various contract conditions for coordination when demand changes due to price change and the effect of promotions. Their work established a foundation for studies on supply chain revenue-sharing (Cachon, 2003; Cachon and Lariviere, 2001a,b, 2005).

Some scholars have investigated the horizontal coordination of supply chains. For example, considering value and physical losses, decision-making under centralized control incapable of effectively coordinating agricultural supply chains. Given the impact of uncertain weather on agricultural production, portfolio risk sharing and buy-back contracts can achieve agricultural product supply chain coordination (Dan and Chen, 2008; Dan et al., 2013, 2014). Another stream of literature has examined vertical supply chain coordination of agricultural products. Mighell and Jones (1963) first proposed the idea of vertical coordination in agricultural product supply chains, referring to the coordination of all activities, including raw material production, processing, storage, transportation, and sales. Hobbs and Young (1999) used transaction cost theory to solve the challenges of vertical coordination of agricultural product supply chain. Wang et al. (2004) proposed using inventory subsidies to achieve supply chain coordination. Supply chain coordination primarily aims to raise the profits of farmers and supermarkets and establish long-term and stable cooperative relationships. Scholars share differing views on how to realize the two goals. The equitability of direct-purchase contracts in developing countries is highly dependent on farmers' production capacity and bargaining power (Stokke, 2009). Capital, technology, law, and policy supervision can improve participants' profits (Luo and Chen, 2015; Tang et al., 2014). 
The studies cited suffer from two problems. First, most of the research focuses on whether revenue-sharing can help to coordinate a supply chain, paying little attention to revenue distribution among supply chain participants. Second, most supply chain revenue-sharing studies are conducted under the assumption that a retailer has a fixed retail price for each product, which presents many limitations. The objective of farmersupermarket direct-purchase model is the establishment of competitive prices for perishable agricultural products and raising total supply chain profits to increase farmers' or farmers' cooperatives profits through revenue-sharing contracts. This paper aims to address these issues by extending the revenue-sharing contract mechanism from a fixed retail price to a variable one.

Four research questions motivate this study: (1) What constitutes the decision-making behavior of retailers and suppliers under centralized control, revenue-sharing contract constraints, and decentralized control considering that perishable agricultural products may decay, market demand may fluctuate, and retailers' promotional efforts may be of benefit? (2) How are the order quantity, retail price, and optimal level of supermarket promotional effort calculated and compared under centralized control, revenue-sharing contract constraints, and decentralized control? (3) Can the introduction of a revenue-sharing parameter in the farmersupermarket direct-purchase model aid the supply chain coordination of perishable agricultural products, and what is a reasonable range of revenue-sharing parameter? (4) Is the expected supply chain coordination under a revenue-sharing farmer-supermarket direct-purchase model verifiable in a real-life case?

The remainder of this paper is organized into four sections. Section 2 presents the research design and model selection. Section 3 describes the model and its assumptions. Section 4 provides an analysis of the model, presenting a case study to support the findings from previous sections with a real-life case. Section 5 presents the research conclusions and implications.

\section{Research design and methods}

\subsection{Research design and data source}

Freshness is one of the key factors that make perishable agricultural products competitive. Due to the short life cycle, as freshness decreases over time, the longer a perishable agricultural product is on the shelf, the less competitive it is on the market and consumers are less willing to buy it. Supermarkets try to increase sales and reduce losses by offering discounts or reducing prices at a certain time based on product freshness. In addition, promotional activities are often conducted through advertising, discounts, and coupons, to increase the consumer flow. If the supermarket alone bears the cost of promotion, as a rational business entity, the supermarket will determine the promotional effort based on the principle of individual profit maximization and benefit from any gains. As a result, the profits of the entire supply chain will not be maximized.

The Newsboy model offers an answer to the problem of determining order quantity for maximum expected profits under stochastic market demand. The model assumes that when the quantity ordered exceeds the quantity demanded, excess inventory will be disposed of through discounts or clearance at the end of the product's sales cycle. When the quantity demanded exceeds the quantity ordered, profit loss will occur. The Newsboy model is widely used in supply chain coordination under stochastic demand research. Whitin (1963) established a Newsboy model that considered price factors and introduced sales prices as endogenous variables for research. Cachon (2003) analyzed the supply chain contract model with the assumption that both demand and price are relevant, identifying reasons for most supply chain contracts' failure to coordinate a supply chain. Examining the challenges of farmers' cooperatives and supermarkets based on the farmersupermarket direct-purchase model, this research expands the Newsboy model, by introducing a revenuesharing contract amid prices affected by stochastic market demand and supermarket promotional efforts.

Data used in this study were obtained from the National Bureau of Statistics of the People's Republic of China (2019), Statistical Bureau of Xuwen County, Zhanjiang City (2019), General Administration of Customs 
of the People's Republic of China (2019). All the data used in this study are officially published, which are authoritative and can guarantee the data quality of this research.

\subsection{Research methods}

Definition 1: The retail price is $a$, the wholesale price is $\mathrm{b}$, the buy-back price is $\mathrm{c}$, and $a>\mathrm{b}>\mathrm{c}$. For every newspaper sold, the newsboy earns $a-\mathrm{b}$. For every newspaper that is left, the newsboy losses b-c.

Definition 2: Within a reasonable range, the probability of daily newspaper demand $\mathrm{r}$ is $f(r)$.

Definition 3: The newsboy buys n newspapers, and the average income is $G(n)$.

Stochastic demand $r$ can be less than, equal to, or greater than $\mathrm{n}$. When the demand is less than the supply, or when $r \leq n$, the newsboy will sell $r$ copies and returns $n-r$ copies. When the demand is greater than the supply, or when $r>n$, the newsboy will sell all newspapers ordered. In general, uncertain demand $r$ and order quantity $\mathrm{n}$ are large. Also, $\mathrm{r}$ has greater analytical significance theoretically if it is regarded as a continuous variable. Here, probability $f(r)$ is converted into a probability density function $\mathrm{p}(\mathrm{r})$.

Based on the above assumptions, the average income $G(n)$ of the newsboy can be obtained as follows:

$$
\mathrm{G}(\mathrm{n})=\int_{0}^{n}[(a-b) r-(b-c)(n-r)] p(r) d r+\int_{n}^{\infty}(a-b) n p(r) d r
$$

The newsboy model problem poses the problem of finding $\mathrm{n}$ to maximize $\mathrm{G}(\mathrm{n})$, given $\mathrm{p}(\mathrm{r})$ and $a, \mathrm{~b}, \mathrm{c}$.

Take the derivative of both sides of Equation 1 with the respect to $\mathrm{n}$ and let $\frac{\mathrm{dG}}{\mathrm{dn}}=0$ :

$$
\frac{\int_{0}^{n} p(r) d r}{\int_{n}^{\infty} p(r)}=\frac{a-b}{b-c}
$$

Order quantity $n^{*}$ can be determined from Equation 2 to maximize expected profit $G\left(n^{*}\right)$. In Figure $1, P_{1}$ and $P_{2}$ represent the areas of the two parts under the $p(r)$ curve. Therefore, the above equation can be written as:

$$
\frac{p_{1}}{p_{2}}=\frac{a-b}{b-c}
$$

The probability of the newspapers not being sold out, or when $\mathrm{r}<\mathrm{n}$, is $p_{1}=\int_{0}^{n} p(r) d r$; that of the newspapers that are sold out, or when $\mathrm{r} \geq \mathrm{n}$, is $p_{2}=\int_{n}^{\infty} p(r) d r$. According to Equation 3, the quantity ordered should make the ratio of the probability of the newspapers not being sold out to that of being sold out equal to the ratio of the money earned for selling one copy of newspaper, or $(a-b)$, to the money lost for surplus of one copy of newspaper, or $(b-c)$. The greater the ratio is, the larger the order quantity.

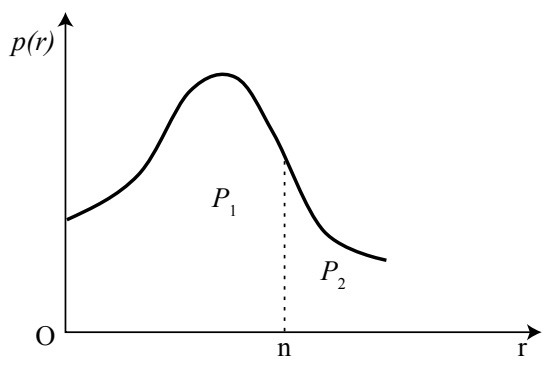

Figure 1. Graphical method to determine $\mathrm{n}$ from $p(r)$. 


\section{The agricultural products supply chain revenue-sharing contract model}

\subsection{Hypotheses and basic variables}

Hypotheses are defined below:

H1: The single perishable agricultural product supply chain under farmer-supermarket direct-purchase is a second-order supply chain consisting of a single supplier and a single retailer. The supplier is cooperative $\mathrm{C}$ and the retailer is supermarket $\mathrm{S}$.

H2: Assuming that cooperative $\mathrm{C}$ and supermarket $\mathrm{S}$ are independent of each other, the products provided by cooperative $\mathrm{C}$ can meet the order requirements of supermarket $\mathrm{S}$.

H3: The market demand for perishable agricultural products is stochastic, and is affected by product price $\mathrm{p}$ and supermarket promotional effort e. Since perishable agricultural products are seasonal, with short life cycles and long lead times, supermarket $\mathrm{S}$ has only one chance to place an order.

H4: All products can be sold out at the end of the cycle with no surplus.

H5: Information concerning market demand, retail price, inventory cost, and handling cost related to the product is symmetrical. Supermarket $\mathrm{S}$, the supply chain leader, has access to all required information, and can correctly judge the market demand to make the best decision.

H6: The supplier and retailer are both risk-neutral and completely rational, and make decisions based on the principle of expected profit maximization.

H7: The game sequence is RSR. The two parties first negotiate to determine the revenue-sharing parameter $\phi$ of supermarket $\mathrm{S}$. Cooperative $\mathrm{C}$ then determines the wholesale price of a unit of product $\mathrm{w}$. Then supermarket $\mathrm{S}$ determines the optimal order quantity $\mathrm{Q}$, retail price $\mathrm{p}$ (an endogenous variable), and promotional effort e based on wholesale price $\mathrm{w}$ of cooperative $\mathrm{C}$.

H8: Promotional activities organized by supermarket $\mathrm{S}$ can increase market demand for the perishable agricultural products, so both supermarket $\mathrm{S}$ and cooperative $\mathrm{C}$ will obtain more profits, and the promotion cost will be assumed by both the supplier and the retailer.

H9: The retail price of the product is an endogenous decision variable of supermarket $\mathrm{S}$, which is determined according to information it has and the principle of maximizing its own profit.

The basic variables of the model are defined below based on the above assumptions:

c $\quad-$ Unit production cost of the perishable agricultural product.

$c_{r} \quad-$ Unit selling cost of the perishable agricultural product (expenses paid for everything else other than cooperative C).

w - Unit wholesale price of the perishable agricultural product.

$\mathrm{p} \quad-$ Unit retail price of the perishable agricultural product.

$\mathrm{V} \quad-$ Unit handling price of surplus perishable agricultural product.

Q - Supermarket order quantity.

$\phi \quad-$ Revenue-sharing parameter, or the ratio of supermarket sales revenue to total sales revenue.

$(1-\phi) \quad-$ Ratio of cooperative sales revenue to total sales revenue.

$\mathrm{d}(\mathrm{p}) \quad-$ Market demand related to the price of the perishable agricultural product.

$\mathrm{S}(\mathrm{Q}, \mathrm{p}, \mathrm{e})$ - The actual market demand of the perishable agricultural product.

$\mathrm{e}(\mathrm{e} \geq 0) \quad-$ Supermarket promotional effort. 
$\gamma(\mathrm{e}) \quad-$ The corresponding demand growth as a result of the promotional effort e. $\gamma(\mathrm{e})$ is the continuous, non-negative and double differentiable increasing function of $\mathrm{e}$ and $\gamma(\mathrm{e}) \dot{ }>0, \gamma(\mathrm{e}) \ddot{<}<0$.

$c(\mathrm{e}) \quad-$ Cost of supermarket effort. $\mathrm{c}(0)=0, c(e)^{\circ}>0$, and $c(e)^{*}>0 . \mathrm{F}(d \mid e)$ is the demand distribution function of promotional effort e.

$\xi \quad-$ The stochastic variable that affects demand.

$f(\xi) \quad-$ The probability density function of $\xi$.

$F(\xi) \quad-$ The distribution function of $\xi \cdot \overline{F(\xi)}=1-F(\xi)$.

$\mathrm{X}(\mathrm{p}, \mathrm{e}, \xi)$ - The stochastic market demand function of the perishable agricultural product.

$f(x \mid p, e) \quad$ - The probability density function of stochastic demand $\mathrm{x}$.

$F(x \mid p, e) \quad-$ The distribution function of stochastic demand $\mathrm{x}$ and $F(x \mid e)=F(x-d(p)-\gamma(e))$.

Market demand for perishable agricultural products is affected by uncertain factors such as the weather, causing it to fluctuate. It is also a function of the retail price of the perishable products and the promotional effort of supermarket $\mathrm{S}$. When the promotional effort of the supermarket $\mathrm{S}$ is e, market demand is $\mathrm{X}(\mathrm{p}, \mathrm{e}, \xi)$, and its corresponding demand probability density function and demand distribution function are $f(x \mid p, e)$ and $F(x \mid p, e)$, respectively, in which $F(x \mid p, e)$ is a continuous differentiable function. Since the market demand for the perishable agricultural product is an increasing function of the promotional effort $\mathrm{e}$, then $\frac{\partial F(x \mid p, e)}{\partial \mathrm{e}}>0$. Since the market demand for the perishable agricultural product is a decreasing function of the unit retail price, then $\frac{\partial F(x \mid p, e)}{\partial \mathrm{p}}<0$.

Assume that the market demand function of the perishable agricultural product is:

$$
\mathrm{X}(\mathrm{p}, \mathrm{e}, \xi)=a-\mathrm{bp}+\gamma(\mathrm{e})+\xi
$$

Let $\mathrm{d}(\mathrm{p})=a-\mathrm{bp}$, in which $a(a>0)$ is the market size of the product and $\mathrm{b}(\mathrm{b}>0)$ is the sensitivity coefficient of the demand price. $\xi$ represents non-erasable market stochastic factors that are irrelevant to the unit retail price $\mathrm{p}$ and promotional effort e of supermarket $\mathrm{S} . f(\xi)$ and $F(\xi)$ are the probability density function and the cumulative distribution function of $\xi$, respectively. $F(\xi)$ is a continuous differentiable function.

Supermarket $\mathrm{S}$ needs to determine order quantity $\mathrm{Q}$, retail price $\mathrm{p}$, and promotional effort e prior to determining the actual market demand of the perishable agricultural product.

Let $Q=z+d(p)+\gamma(e) . S(Q, p, e)$ represents the expected quantity of sales of supermarket $S$ with the given order quantity $\mathrm{Q}$, retail price $\mathrm{p}$ and promotional effort $\mathrm{e}$, which is:

$$
\begin{aligned}
\mathrm{S}(\mathrm{Q}, \mathrm{p}, \mathrm{e}) & =\mathrm{E}\{\min [Q, X(p, \xi, e)]\}=\mathrm{E}\{d(p)+\gamma(e)+\min (z, \xi)\} \\
& =\mathrm{d}(\mathrm{p})+\gamma(\mathrm{e})+\left[z-\int_{0}^{z} F(\xi) d \xi\right]=\mathrm{Q}-\int_{d(p)+\gamma(e)}^{Q} F(x-d(p)-\gamma(e)) d x
\end{aligned}
$$

Then, the expected quantity of surplus of supermarket $S$ is $I(Q)=E(Q-S(Q, p, e))=Q-S(Q, p, e)$.

\subsection{Establishment of model}

The given model assumptions indicate that the profit functions of supermarket $\mathrm{S}$, cooperative $\mathrm{C}$, and the entire supply chain can be combined with the revenue-sharing contract of the perishable agricultural product under the farmer-supermarket direct-purchase model. At the beginning of the retail cycle, supermarket $\mathrm{S}$ and cooperative $\mathrm{C}$ negotiate to determine the size of the revenue-sharing parameter of supermarket $\mathrm{S}$. The 
expressions of the expected profit function of supermarket $\mathrm{S}$, that of cooperative $\mathrm{C}$, and that of the entire supply chain can then be obtained.

The expected profit function of supermarket $\mathrm{S}$ is:

$$
\begin{aligned}
\Pi_{s} & =\phi p S(Q, p, e)-w Q-c_{r} Q+\phi v[Q-S(Q, p, e)]-\phi c(e) \\
& =\left(\phi \mathrm{p}-\mathrm{w}-c_{r}\right) Q-\phi(p-v) \int_{d(p)+\gamma(e)}^{Q} F[x-d(p)-\gamma(e)] d x-\phi c(e) \\
& =\left(\phi \mathrm{p}-\mathrm{w}-c_{r}\right)[z+d(p)+\gamma(e)]-\phi(p-v) \int_{0}^{z} F(\xi) d \xi-\phi c(e)
\end{aligned}
$$

The expected profit function of cooperative $\mathrm{C}$ is:

$$
\begin{aligned}
\Pi_{C} & =(1-\phi) p S(Q, e)+w Q-c Q+(1-\phi) v[Q-S(Q, e)]-(1-\phi) c(e) \\
& =[(1-\phi) p+w-c] Q-(1-\phi)(p-v) \int_{d(p)+\gamma(e)}^{Q} F[x-d(p)-\gamma(e)] d x-(1-\phi) c(e) \\
& =[(1-\phi) p+w-c][z+d(p)+\gamma(e)]-(1-\phi)(p-v) \int_{0}^{z} F[\xi] d \xi-(1-\phi) c(\mathrm{e})
\end{aligned}
$$

The expected profit function of the entire supply chain is:

$$
\begin{aligned}
\Pi_{L} & =\Pi_{S}+\Pi_{C}=p S(Q, p, e)-c Q-c_{r} Q+v[Q-S(Q, p, e)]-c(e) \\
& =\left(p-c-c_{r}\right) Q-(p-v) \int_{d(p)+\gamma(e)}^{Q} F[x-d(p)-\gamma(e)] d x-c(e) \\
& =\left(p-c-c_{r}\right)[z+d(p)+\gamma(e)]-(p-v) \int_{0}^{z} F[\xi] d \xi-c(e)
\end{aligned}
$$

\section{Model analysis}

First, order quantity, retail price, and promotional effort of supermarket $\mathrm{S}\left(Q^{\prime}, p^{\prime}, e^{\prime}\right)$ under centralized control for maximum expected profits of the supply chain are calculated. Then, decision-making behavior under the supply chain revenue-sharing model is analyzed and order quantity, retail price, and promotional effort of supermarket $\mathrm{S}\left(Q^{*}, p^{*}, e^{*}\right)$ are determined for maximum expected profits of supermarket $\mathrm{S}$. Next, decisionmaking behavior under decentralized control with the absence of the revenue-sharing is estimated, and the order quantity, retail price, and promotional effort of supermarket $\mathrm{S} \mathrm{Q}^{* *}, \mathrm{p}^{* *}, \mathrm{e}^{* *}$ for maximum expected profits of supermarket S are determined. These values are then substituted into cooperative C's expected profits function to determine the wholesale price $\mathrm{w}$ for maximum profits of cooperative $\mathrm{C}$, identifying the hidden function relationship between these values prior to solving the range of revenue-sharing parameter $\phi$ of supermarket $\mathrm{S}$.

\subsection{Analysis of decision-making behavior under centralized control}

The supply chain under centralized control, supermarket $\mathrm{S}$ and cooperative $\mathrm{C}$ is a unit and there is complete cooperation between them, the purpose of which is to maximize the profits of the supply chain.

Given the expected profits function of the entire supply chain under centralized control is Equation 6, take the first partial derivative of Equation 6 with respect to $\mathrm{z}$, $\mathrm{p}$, and e, and let the first-order partial derivative be zero, obtaining:

$$
\begin{aligned}
& p^{\prime}=\frac{z+a+\gamma(e)+b c+b c_{r}-\int_{0}^{z} F(\xi) d \xi}{2 b} \\
& z^{\prime}=F^{-1}\left(\frac{P^{\prime}-C-C_{r}}{P^{\prime}-V}\right) \\
& \frac{c^{\prime}\left(e^{\prime}\right)}{\gamma^{\prime}\left(e^{\prime}\right)}=p-c-c_{r}
\end{aligned}
$$

Given the values of $\mathrm{v}, \mathrm{c}$, and $c_{r}$ and the expressions of $\mathrm{d}(\mathrm{p}), \mathrm{c}(\mathrm{e})$, and $\gamma(\mathrm{e})$, the optimal solution $\left(z^{\prime}, p^{\prime}, e^{\prime}\right)$ for the maximum profits of the entire supply chain is achieved. Here, $p$ ' is the unit retail price determined by 
supermarket $\mathrm{S}$ when the entire supply chain of the perishable agricultural product has the maximum profits under centralized control. $e$ ' is the promotional effort of supermarket $\mathrm{S}$ in the same conditions. Substituting $\left(z^{\prime}, p^{\prime}, e^{\prime}\right)$ into $\mathrm{Q}=\mathrm{z}+\mathrm{d}(\mathrm{p})+\gamma(\mathrm{e})$, obtains $Q^{\prime}=z^{\prime}+d\left(p^{\prime}\right)+\gamma\left(e^{\prime}\right)$, in which $Q^{\prime}$ is the optimal order quantity of supermarket $\mathrm{S}$ when the entire supply chain of the perishable agricultural product has the maximum profit under centralized control. Substituting $\left(Q^{\prime}, p^{\prime}, e^{\prime}\right)$ into Equation 6 , will derive the maximum expected profit $\Pi^{\prime}{ }_{L}$ of the entire supply chain under centralized control:

$$
\Pi_{L}^{\prime}=\left(p^{\prime}-c-c_{r}\right) Q^{\prime}-\left(p^{\prime}-v\right) \int_{d\left(p^{\prime}\right)+\gamma\left(e^{\prime}\right)}^{Q^{\prime}} F\left(x-d\left(p^{\prime}\right)-\gamma\left(e^{\prime}\right)\right) d x-c\left(e^{\prime}\right)
$$

Based on the above analysis, the maximum expected profit of the entire supply chain of the perishable agricultural product under centralized control is $\Pi_{L}{ }_{L}$. The unit retail price, optimal promotional effort, and optimal order quantity of supermarket $\mathrm{S}$ are $p^{\prime}, e^{\prime}$ and $Q^{\prime}$, respectively.

\subsection{Analysis of decision-making behavior under the supply chain revenue-sharing model}

Under the supply chain revenue-sharing contract model, supermarket S purchases Q perishable agricultural product from cooperative $\mathrm{C}$ at a relatively low wholesale price $\mathrm{w}$. The two parties sign a contract, which stipulates that supermarket $\mathrm{S}$ shares $(1-\phi)$ of the revenue with cooperative $\mathrm{C}$ when the sales cycle ends. Meanwhile, cooperative $\mathrm{C}$ also bears $(1-\phi)$ of the promotion cost $\mathrm{c}(\mathrm{e})$ of supermarket $\mathrm{S}$. The purpose of using revenue-sharing contracts in the supply chain is to ensure that the overall profits of the supply chain reach the level under centralized control. There is a Stackelberg game relationship between supermarket $\mathrm{S}$ and cooperative $\mathrm{C}$, in which supermarket $\mathrm{S}$ is the leader and cooperative $\mathrm{C}$ is the follower.

According to the regression and induction analysis method, the decision-making behavior of supermarket $\mathrm{S}$ is analyzed first. Under the supply chain revenue-sharing contract, according to the expression of the expected profits function of supermarket $S$, the unit retail price $\mathrm{p}$, order quantity $\mathrm{Q}$, and promotional effort e for maximum expected profits of supermarket $\mathrm{S}$ are determined.

Given Equation 4 is the expected profits function of supermarket $S$, taking the first partial derivative of Equation 4 with respect to $\mathrm{z}, \mathrm{p}$, and e, and letting the first-order partial derivative to be zero, derives:

$$
\begin{aligned}
& z^{*}=F^{-1}\left(\frac{\phi p-w-c_{r}}{\phi(p-v)}\right) \\
& p^{*}=\frac{z+a+\gamma(e)-\int_{0}^{L} F(\xi) d \xi}{2 b}+\frac{w+c_{r}}{2 \phi} \\
& \frac{\phi c^{\prime}\left(e^{*}\right)}{\gamma^{\prime}\left(e^{*}\right)}=\phi p-w-c_{r}
\end{aligned}
$$

Given the values of $\mathrm{v}, \mathrm{w}, c_{r}$, and the expressions of $\mathrm{F}(\mathrm{x}), \mathrm{c}(\mathrm{e})$, and $\gamma(\mathrm{e})$, the optimal solution is $\left(z^{*}, p^{*}, e^{*}\right)$. Here, $p^{*}$ is the unit retail price of supermarket $\mathrm{S}$ when it reaches maximum profits under the supply chain revenue-sharing contract. $e^{*}$ is the promotional effort of supermarket $\mathrm{S}$ when it reaches the maximum profits under the supply chain revenue-sharing contract. Substituting $\left(z^{*}, p^{*}, e^{*}\right)$ into $\mathrm{Q}=\mathrm{z}+\mathrm{d}(\mathrm{p})+\gamma(\mathrm{e})$, elicits $Q^{*}=z^{*}+d\left(p^{*}\right)+\gamma\left(e^{*}\right)$, in which $Q^{*}$ indicates the order quantity of supermarket $\mathrm{S}$ when it reaches the maximum profits under the supply chain revenue-sharing contract.

Substituting $\left(Q^{*}, p^{*}, e^{*}\right)$ into the expected profits function Equation 4 of supermarket $\mathrm{S}$, determines the maximum expected profits of supermarket $\mathrm{S}$ :

$$
\Pi_{S}^{*}=\left[\phi p^{*}-w-c_{r}\right] Q^{*}-\phi\left(p^{*}-v\right) \int_{d\left(p^{*}\right)+\gamma\left(e^{*}\right)}^{Q^{*}} F\left[x-d\left(p^{*}\right)-\gamma\left(e^{*}\right)\right] d x-\phi c\left(e^{*}\right)
$$

Substituting $\left(Q^{*}, p^{*}, e^{*}\right)$ into the expected profits function Equation 5 of cooperative $\mathrm{C}$, elicits the maximum expected profits of cooperative $\mathrm{C}$ : 


$$
\begin{aligned}
\Pi_{c}^{*}= & {\left[(1-\phi) p^{*}+w-c\right] Q^{*}-(1-\phi)\left(p^{*}-v\right) \int_{d\left(p^{*}\right)+\gamma\left(e^{*}\right)}^{Q^{*}} F\left[x-d\left(p^{*}\right)-\gamma\left(e^{*}\right)\right] d x-} \\
& (1-\phi) c\left(e^{*}\right)
\end{aligned}
$$

With the constraint of the supply chain revenue-sharing contract, the decision made by supermarket $\mathrm{S}$ aligns the revenue of the entire supply chain with profits for the entire supply chain under centralized control. That is, it makes $\pi_{L}^{*}=\pi_{S}^{*}+\pi_{C}^{*}=\pi_{L}^{\prime}$ hold. The necessary condition of this equation is $\left(Q^{*}, p^{*}, e^{*}\right)=\left(Q^{\prime}, p^{\prime}, e^{\prime}\right)$, or $\left(z^{*}, p^{*}, e^{*}\right)=\left(z^{\prime}, p^{\prime}, e^{\prime}\right)$. Comparing Equation 8 and Equation 11 elicits $\mathrm{w}=\phi\left(\mathrm{c}+c_{r}\right)-c_{r}$.

Substituting $\mathrm{W}=\phi\left(\mathrm{c}+c_{r}\right)-c_{r}$ into Equation 14, the expected profits function of supermarket $\mathrm{S}$, we get:

$$
\begin{aligned}
& \Pi_{\mathrm{S}}^{*}=\phi\left(\mathrm{p}^{*}-\mathrm{c}-\mathrm{c}_{\mathrm{r}}\right) \mathrm{Q}^{*}-\phi\left(\mathrm{p}^{*}-\mathrm{v}\right) \int_{\mathrm{d}\left(\mathrm{p}^{*}\right)+\gamma\left(\mathrm{e}^{*}\right)}^{\mathrm{Q}^{*}} \mathrm{~F}\left[\mathrm{x}-\mathrm{d}\left(\mathrm{p}^{*}\right)-\gamma\left(\mathrm{e}^{*}\right)\right] \mathrm{dx}-\phi \mathrm{c}\left(\mathrm{e}^{*}\right) \\
& \Pi_{\mathrm{c}}^{*}=\Pi_{\mathrm{L}}^{*}-\Pi_{\mathrm{S}}^{*}=(1-\phi) \Pi_{\mathrm{L}}^{\prime}
\end{aligned}
$$

\subsection{Analysis of decision-making behavior under decentralized control}

Without the constraints of a supply chain revenue-sharing contract, the decision-making behavior between supply chain participants is a dynamic game, in which the leader is the retailer supermarket $\mathrm{S}$ and the supplier is cooperative $\mathrm{C}$. In the first stage, supermarket $\mathrm{S}$ predicts the market demand for the perishable agricultural product based on the information it has, and then determines order quantity $Q$, retail price $\mathrm{p}$, and promotional effort e to maximize its own profits based on the demand.

Assuming that the unit wholesale price determined by cooperative $\mathrm{C}$, in case of decentralized decisionmaking, the expected profits functions of supermarket $\mathrm{S}$ and cooperative $\mathrm{C}$ are obtained according to the above assumptions.

The expected profits function of supermarket $\mathrm{S}$ is:

$$
\begin{aligned}
\Pi_{S} & =\left(p-w-c_{r}\right)[z+d(p)+\gamma(e)]-(p-v) \int_{0}^{z} F(\xi) d \xi-c(e) \\
& =\left(p-w-c_{r}\right) Q-(p-v) \int_{d(p)+\gamma(e)}^{Q} F[x-d(p)-\gamma(e)] d x-c(e)
\end{aligned}
$$

The expected profits function of cooperative $\mathrm{C}$ is:

$$
\Pi_{\mathrm{C}}=(\mathrm{w}-\mathrm{c})[\mathrm{z}+\mathrm{d}(\mathrm{p})+\gamma(\mathrm{e})]=(\mathrm{w}-\mathrm{c}) \mathrm{Q}
$$

Given Equation 18 is the expected profits function of supermarket $S$, take the first partial derivative of Equation 18 with respect to $\mathrm{z}, \mathrm{p}$, and e, and let $\phi=1$ and the first-order partial derivative be zero, eliciting:

$$
\begin{aligned}
& \mathrm{p}^{* *}=\frac{\mathrm{z}+\mathrm{a}+\mathrm{bw}+\mathrm{b} \mathrm{c}_{\mathrm{r}}+\gamma(\mathrm{e})-\int_{0}^{\mathrm{z}} \mathrm{F}[\xi] \mathrm{d} \xi}{2 \mathrm{~b}} \\
& \mathrm{z}^{* *}=\mathrm{F}^{-1}\left(\frac{\mathrm{p}-\mathrm{w}-\mathrm{c}_{\mathrm{r}}}{\mathrm{p}-\mathrm{v}}\right) \\
& \frac{\mathrm{c}^{\prime}\left(\mathrm{e}^{* *}\right)}{\gamma^{\prime}\left(\mathrm{e}^{* *}\right)}=\mathrm{p}-\mathrm{w}-\mathrm{c}_{\mathrm{r}}
\end{aligned}
$$

Given the values of $\mathrm{v}, \mathrm{w}$ and $\mathrm{c}_{\mathrm{r}}$, and the expressions of $\mathrm{c}(\mathrm{e}), \gamma(\mathrm{e})$ and $\mathrm{F}(\mathrm{x}), \mathrm{p}^{* *}, \mathrm{z}^{* *}, \mathrm{e}^{* *}, \mathrm{p}^{* *}$ indicates the unit retail price determined by supermarket $\mathrm{S}$ when it reaches maximum profits under decentralized decision-making. $\mathrm{e}^{* *}$ is the promotional effort of supermarket $\mathrm{S}$ when it reaches maximum profits under decentralized decision-making. Substituting $\mathrm{p}^{* *}, \mathrm{z}^{* *}$ and $\mathrm{e}^{* *}$ into $\mathrm{Q}=\mathrm{z}+\mathrm{d}(\mathrm{p})+\gamma(\mathrm{e})$, elicits $\mathrm{Q}^{* *}=\mathrm{z}^{* *}+$ $\mathrm{d}\left(\mathrm{p}^{* *}\right)+\gamma\left(\mathrm{e}^{* *}\right)$, in which $\mathrm{Q}^{* *}$ is the order quantity when supermarket $\mathrm{S}$ reaches maximum profits under decentralized decision-making. Substituting $\mathrm{Q}^{* *}$ into Equation 18, the expression of the expected profits of supermarket $\mathrm{S}$ is obtained: 


$$
\Pi_{\mathrm{S}}^{* *}=\left(\mathrm{p}^{* *}-\mathrm{w}-\mathrm{c}_{\mathrm{r}}\right) \mathrm{Q}^{* *}-\left(\mathrm{p}^{* *}-\mathrm{v}\right) \int_{\mathrm{d}\left(\mathrm{p}^{* *}\right)+\gamma\left(\mathrm{e}^{* *}\right)}^{\mathrm{Q}^{* *}} \mathrm{~F}\left[\mathrm{x}-\mathrm{d}\left(\mathrm{p}^{* *}\right)-\gamma\left(\mathrm{e}^{* *}\right)\right] \mathrm{dx}-\mathrm{c}\left(\mathrm{e}^{* *}\right)
$$

In the second stage, cooperative $\mathrm{C}$ determines the wholesale price $\mathrm{w}$ based on order quantity, retail price, and promotional effort of supermarket $\mathrm{S} \mathrm{p}^{* *}, \mathrm{Q}^{* *}, \mathrm{e}^{* *}$. Substituting $\mathrm{p}^{* *}, \mathrm{Q}^{* *}, \mathrm{e}^{* *}$ into Equation 19 , the expected profits function of cooperative $\mathrm{C}$ derives:

$$
\Pi_{\mathrm{C}}^{* *}=(\mathrm{w}-\mathrm{c}) \mathrm{Q}^{* *}=(\mathrm{w}-\mathrm{c})\left[\mathrm{F}^{-1}\left(\frac{\mathrm{p}^{* *}-\mathrm{w}-\mathrm{c}_{\mathrm{r}}}{\mathrm{p}^{* *}-\mathrm{v}}\right)+\mathrm{d}\left(\mathrm{p}^{* *}\right)+\gamma\left(\mathrm{e}^{* *}\right)\right]
$$

\subsection{Analysis of supply chain revenue-sharing contract parameters}

To enable both supermarket $\mathrm{S}$ and cooperative $\mathrm{C}$ to maximize their own profits in the supply chain while ensuring the maximum profits of the entire supply chain, the two parties jointly determine revenue-sharing based on the above assumptions. Under the constraint of a rational economic man, both supermarket $\mathrm{S}$ and cooperative $\mathrm{C}$ will only consider their own interests, and all decisions are made with the aim of maximizing self-interests. Therefore, to ensure that both supermarkets $\mathrm{S}$ and cooperative $\mathrm{C}$ in the supply chain accept the revenue-sharing contract, the profits obtained by both parties under the revenue-sharing contract must not be less than those obtained when each of them makes decisions independently. To ensure that the profits of supermarket $\mathrm{S}$ and cooperative $\mathrm{C}$ in the supply chain under the constraint of the revenue-sharing contract are both Pareto improvement, the following two inequalities must hold.

$$
\Pi_{\mathrm{s}}^{*}>\Pi_{\mathrm{s}}^{* *}, \Pi_{\mathrm{c}}^{*}>\Pi_{\mathrm{c}}^{* *}
$$

Substituting Equation 17 into the above equation, we get:

$$
1-\frac{\Pi_{\mathrm{C}}^{* *}}{\Pi_{\mathrm{L}}^{\prime}}>\phi>\frac{\Pi_{\mathrm{S}}^{* *}}{\Pi_{\mathrm{L}}^{\prime}}
$$

When supermarket $\mathrm{S}$ and cooperative $\mathrm{C}$ design the specific supply chain revenue-sharing contract and discuss the size of contract parameter $\phi$, the value range of $\phi$ should be within the range of the above inequality. Only in this way can supermarket $\mathrm{S}$ and cooperative $\mathrm{C}$ accept this contract. It depends on the respective positions of supermarket $\mathrm{S}$ and cooperative $\mathrm{C}$ in the supply chain and their bargaining power as to which value of $\phi$ should take.

\subsection{Case study}

As the most important tropical fruit, bananas are one of the seven fruits (apples, citrus, pears, bananas, grapes, pineapples, coconuts) included in China's production statistics. Bananas are a typical perishable agricultural product with high storage, transportation, and freshness requirements. The market demand is stochastic and the sales cycle is short. In 2018, China's banana production was 11,221,700 tons, an increase of $0.46 \%$ from $11,169,800$ tons in 2017. China imported 1,544,800 tons and exported 20,200 tons (Data from the General Administration of Customs of the People's Republic of China, 2019). Apparent banana consumption was 12,746,500 tons. According to data from the National Bureau of Statistics of the People's Republic of China (2019), the area of China's banana orchards in 2017 was 351,030 hectares. China has a large banana industry, but individual banana farms are small and not well organized. There are very few large-scale banana farms. The main banana producing areas in China are Guangdong, Guangxi, Hainan, Yunnan, and Fujian, with Guangdong having the highest banana production.

Xuwen County is located in Zhanjiang, Guangdong province. In 2006, it was awarded the title of 'Number 1 county for banana production in China' by the Ministry of Agriculture of China. The banana industry is one of its prominent industries. From the early 1970s to 2018, Xuwen's banana planting area increased from only 1,400 mu (or 93.33 hectares) to as high as 175,000 mu (or 11,666.67 hectares), with an annual output value of 213.1 million US dollars (data from the Statistical Bureau of Xuwen County, Zhanjiang City (2019)). 
The county ranks No.1 in terms of planting area, total production, and annual total output among all Chinese counties. However, most banana farms are run by individual farmers, who are at a disadvantage in negotiating with retailers. Therefore, after China introduced policies to encourage Farmer-Supermarket Direct-Purchase model, Xuwen County also began to establish farmer cooperatives. Nanxia Farmer Cooperative is one of them. Bananas are one of the main agricultural products that the Nanxia Farmer Cooperative grows. The production cost of bananas includes investment cost and management cost. With good management, the production cost of bananas is $\$ 0.29$ per kilo. The market demand for bananas is stochastic, and stochastic variable $\xi$ follows the uniform distribution $\xi \sim \mathrm{U}(-5,5)$.

Tianhong Supermarket has purchased agricultural products from Nanxia Farmer Cooperative for a long time. In the early stage of the cooperation, the two parties did not sign a revenue-sharing contract. Tianhong Supermarket determined the quantity of bananas purchased according to the market information it had and past sales data. The purchase price was determined based on the market wholesale price of bananas. According to the supermarket's sales and prices data, the demand function of bananas is $d(p)=180-20 p$, the market wholesale price is $\$ 0.67$ per kilo. At normal temperature, the shelf life of bananas is 3-5 days, and the best storage temperature is $10.6-17.8^{\circ} \mathrm{C}$. Generally, the longest storage time is 13 days. Tianhong Supermarket generally keeps bananas in the refrigerator to extend their shelf life as much as possible. Measures are also taken to promote sales within the sales cycle. The unit promotional cost is $\$ 0.17$ per kilo. If the quantity of bananas ordered exceeds the market demand, to reduce its own losses, Tianhong Supermarket will offer discounts when the price drops to $\$ 0.29$ per kilo. To increase both parties' profits, Tianhong Supermarket and Nanxia Cooperative altered their traditional cooperation strategy, signing a revenue-sharing contract. When the revenue-sharing contract was signed, it was agreed that promotional costs would be shared by both parties. The corresponding banana demand function is $\gamma(\mathrm{e})=\mathrm{e}$, in which e is the supermarket's promotional effort. The supermarket's promotional effort cost function is $\mathrm{c}(\mathrm{e})=0.5 e^{2}$.

According to the above case study, $\Pi_{\mathrm{s}}^{*}, \Pi_{\mathrm{c}}^{*}$ and $\Pi_{\mathrm{L}}^{*}$ represent the profits of Tianhong supermarket, Nanxia farmer cooperative, and the entire supply chain under the revenue-sharing contract. $\Pi_{\mathrm{s}}^{* *}, \Pi_{\mathrm{c}}^{* *}$ and $\Pi_{\mathrm{L}}^{* *}$ represent profits under decentralized control $\mathrm{w}$ and $w^{D}$ represent the wholesale prices under the revenue-sharing contract and under decentralized control. Based on the given data, the related equations are solved using MATLAB (The Mathworks, Natick, MA, USA) obtaining: $\mathrm{e}^{*}=3.2, \mathrm{p}^{*}=0.71, \mathrm{z}^{*}=0.9, \mathrm{Q}^{*}=91.4, \Pi_{\mathrm{L}}^{*}=42.31, \mathrm{e}^{* *}=3.1$, $\mathrm{p}^{* *}=0.87, \mathrm{z}^{* *}=0.12, \mathrm{Q}^{* *}=63.9, \Pi_{\mathrm{s}}^{* *}=27.43, \Pi_{\mathrm{c}}^{* *}=12.04$, and $0.096<\phi<0.109$, and eliciting a comparison of numerical values of the parameter under the revenue-sharing contract and decentralized control (Table 1).

When Tianhong supermarket and Nanxia farmer cooperative do not sign a revenue-sharing contract, the supermarket purchases at a wholesale price of $\$ 0.67$ per kilo and the optimal order quantity of Tianhong supermarket is $31.95 \mathrm{~kg}$. In this case, the supermarket's sales profit is $\$ 27.43$, the cooperative's profit is

Table 1. Comparison of numerical values of the parameters under revenue-sharing contract and decentralized control. ${ }^{1,2}$

\begin{tabular}{lllllllllll}
\hline $\boldsymbol{\phi}$ & $\boldsymbol{w}$ & $\boldsymbol{w}^{\boldsymbol{D}}$ & $\boldsymbol{Q}^{*}$ & $\boldsymbol{Q}^{* *}$ & $\boldsymbol{\Pi}_{\boldsymbol{s}}^{*}$ & $\boldsymbol{\Pi}_{\boldsymbol{c}}^{*}$ & $\boldsymbol{\Pi}_{\boldsymbol{L}}^{*}$ & $\boldsymbol{\Pi}_{\boldsymbol{s}}^{* *}$ & $\boldsymbol{\Pi}_{\boldsymbol{c}}^{* * *}$ & $\boldsymbol{\Pi}_{\boldsymbol{L}}^{* * *}$ \\
\hline 0.097 & 0.078 & 0.33 & 91.4 & 63.9 & 27.49 & 14.81 & 42.31 & 27.43 & 12.04 & 39.47 \\
0.099 & 0.081 & 0.33 & 91.4 & 63.9 & 27.86 & 14.44 & 42.31 & 27.43 & 12.04 & 39.47 \\
0.100 & 0.083 & 0.33 & 91.4 & 63.9 & 28.27 & 14.03 & 42.31 & 27.43 & 12.04 & 39.47 \\
0.102 & 0.086 & 0.33 & 91.4 & 63.9 & 28.69 & 13.62 & 42.31 & 27.43 & 12.04 & 39.47 \\
0.103 & 0.088 & 0.33 & 91.4 & 63.9 & 29.10 & 13.21 & 42.31 & 27.43 & 12.04 & 39.47 \\
0.104 & 0.091 & 0.33 & 91.4 & 63.9 & 29.51 & 12.80 & 42.31 & 27.43 & 12.04 & 39.47 \\
0.106 & 0.093 & 0.33 & 91.4 & 63.9 & 29.92 & 12.39 & 42.31 & 27.43 & 12.04 & 39.47 \\
\hline
\end{tabular}

${ }^{1}$ Data of wholesale price, promotional cost and discount prices are from the Statistical Bureau of Xuwen County, Zhanjiang City (2019).

${ }^{2}$ Exchange rate of RMB against US dollar is 1 US dollar equals 6.9 yuan RMB, 2020. 
$\$ 12.04$, and the entire supply chain's profit is $\$ 39.47$. When Tianhong supermarket and Nanxia farmer cooperative sign a revenue-sharing contract and agree that revenue-sharing parameter of the supermarket is 0.097 , then the optimal order quantity of Tianhong supermarket is $45.7 \mathrm{~kg}$, which is larger than the optimal order quantity when no revenue-sharing contract is signed. That is, the maximum order quantity under the revenue-sharing contract is larger than the maximum order quantity under decentralized control. The wholesale price of the supermarket drops to $\$ 0.156$ per kilo, the supermarket's profit is $\$ 27.49$. Nanxia cooperative's profit is $\$ 14.81$, the entire supply chain's profit is $\$ 42.31$, all of which are greater than the profit s under decentralized control. As the parameter of revenue-sharing becomes larger, the supermarket's wholesale price and profit will increase, whereas the profit of Nanxia cooperative will decrease. As long as the revenue-sharing parameter is between 0.096 and 0.109 the profits of Tianhong supermarket, Nanxia cooperative, and the entire supply chain will be greater than the profits under decentralized control.

Figures 2 and 3 present the trend of profit change of Tianhong supermarket and Nanxia farmer cooperative, demonstrating that the revenue-sharing coefficient exerts opposing profit impacts on the supermarket's and cooperative's profits. The supermarket's profits increase as the revenue-sharing coefficient increases, whereas the cooperative's profits decrease as the revenue-sharing coefficient increases. To some extent, the revenue-sharing coefficient reflects the bargaining power of the supermarket and the cooperative in the supply chain. The larger the revenue-sharing parameter, the more obvious the supermarket's dominant position in the supply chain.

This case demonstrates that the revenue-sharing contract model under farmer-supermarket direct-purchase is a win-win option for both participants in the supply chain. Bananas are a typical perishable agricultural product, and this case demonstrates that the supply chain revenue-sharing contract under direct-purchase applies to other perishable agricultural products. Under the revenue-sharing contract model, each participant

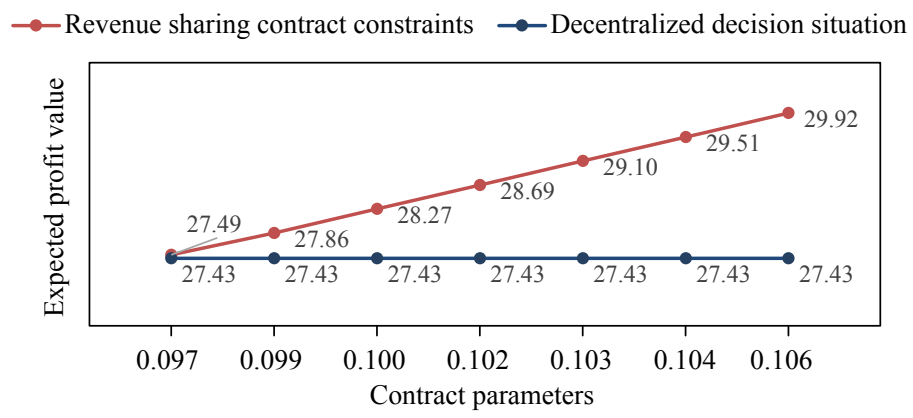

Figure 2. Comparison of the supermarket's expected profit.

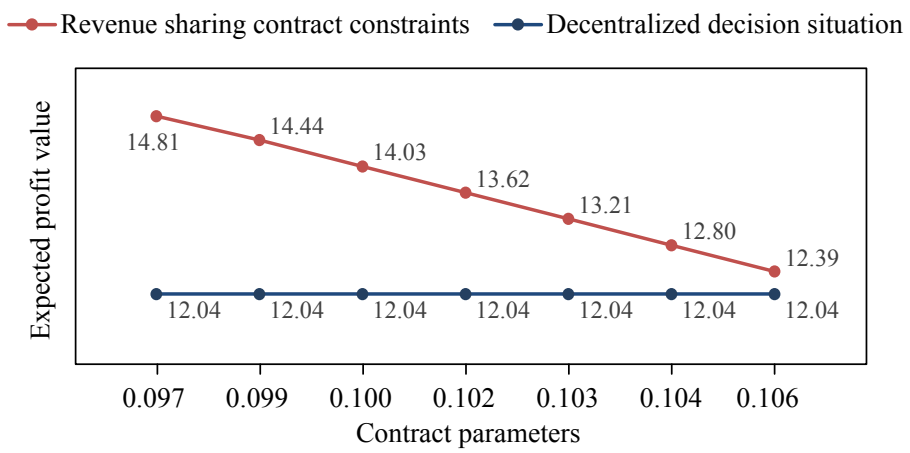

Figure 3. Comparison of the cooperative's expected profit. 
can obtain higher profits than in the case of decentralized control. The size of the revenue-sharing parameter depends on the bargaining power of the cooperative and the supermarket.

\section{Conclusions and implications}

\subsection{Conclusions}

The decision-making behavior of retailers and suppliers were analyzed under the circumstances of centralized control, a supply chain revenue-sharing contract, and decentralized control. By calculating and comparing the optimal order quantity, retail price, and the supermarket's promotional effort under the above three circumstances, five notable findings emerged:

- Under the constraints of the supply chain revenue-sharing contract, the optimal order quantity of the supermarket is greater than that under decentralized control.

- Under the constraint of the supply chain revenue-sharing contract, since the promotion cost is shared by the supermarket and the cooperative, to maximize the profit, the supermarket is more motivated to implement promotion. Therefore, promotional effort is stronger than under decentralized control.

- As the supermarket's revenue-sharing parameter increases, the wholesale price determined by the cooperative will also increase. However, cooperative profit will decrease as the revenue-sharing parameter increases. In contrast, supermarket profit will increase as the revenue-sharing parameter increases.

- Under the constraint of the supply chain revenue-sharing contract, the overall profits of the supply chain are higher than that of decentralized control, and the profits of the supermarket and the cooperative are also higher than their respective profits in the case of decentralized control. This implies that when a supermarket and a cooperative sign a supply chain revenue-sharing contract, both parties obtain higher profit than under decentralized control making independent decisions. As a result, the involved parties will not be motivated to choose other supply chain models. Therefore, the introduction of a revenue-sharing contract can achieve long-term stability in supply chain coordination and cooperation.

- The revenue-sharing parameter has a reasonable value range. In the end, the value depends on the position of the supplier and the retailer in the supply chain and their bargaining power.

This study analyzes how supermarkets and farmers work together through a contract to realize mutual benefits while remaining independent. Introducing revenue-sharing contracts into farmer-supermarket direct-purchase supply chains and building a revenue-sharing contract model for perishable agricultural products, can achieve long-term stability of supply chain coordination, every participant in a supply chain obtains higher profits, and the size of the revenue-sharing parameter depends on positions of every participant in the supply chain and their bargaining power.

\subsection{Implications and future research}

Unstable cooperation among supply chain participants leads to the inequitable distribution of revenue. The establishment of a fair revenue distribution mechanism that benefits from direct, long-term cooperation between farmers and supermarkets is one of the most outstanding problems. Farmer-supermarket directpurchase model directly connects many individual farmers with supermarkets, which effectively solves the problem of selling agricultural products, as well as improving farmers and supermarkets profits and allows for the availability of fresh agricultural products to consumers; a triple-win for supermarkets, farmers, and consumers. This study on this issue has practical significance. With the support of Chinese national policies, and joint efforts of farmers and supermarkets, farmer-supermarket direct-purchase model played an important role in poverty reduction and agricultural development in China.

Farmer-supermarket direct-purchase as a supply chain for agricultural products is not unique to China, as most countries have adopted this model. However, it is a relatively new practice in China. there are many 
issues that need to be addressed. The Chinese government is the initiator of the farmer-supermarket directpurchase model and serves as a link between the suppliers and the retailers. Therefore, it has gradually become a strong supporter and advocate of the supply chain of perishable agricultural products under the farmer-supermarket direct-purchase model and focused on creating a sound policy environment to facilitate the management of the supply chain. Countries and regions like the US, Europe and Africa have a quite established farmer-supermarket direct-purchase model since they started to develop it in the 1970s and 1980s. China, with its late start time and different stages of development, has a lot to learn from them. The direct-purchase model is a model in the agricultural product supply chain shared around the world. Therefore, research has generality. However, the direct-purchase model is a relatively new practice in China. So, the problems it generates are unique to China. This deserves attention of scholars abroad.

The existing research on supply chain contract is limited to the second-order supply chain consisting of single supplier and single retailer, this study analyzes the farmer-supermarket direct-purchase supply chain composed of supermarkets and farmers. Therefore, in the future, researchers can explore more complex suppliers $n(n \geq 1)$, corresponding to $n(n \geq 1)$ each retailer, or to the expansion of the multi-section supply chain. In addition, perishable agricultural products are very special and complex, if the market demand forecast is inaccurate, or greatly increased or decreased due to unexpected events (Coronavirus or disaster), if the order quantity of the supermarket cannot meet the sudden increase of market demand, the rescue will produce a large hidden loss. So, except for considering that perishable agricultural products may decay, market demand may fluctuate, and retailers' promotional efforts may be of benefit, researchers can proceed from more dimensions in future research. Such as, considering the problem of government's subsidy policy to the supply chain member's profit and the social welfare improvement. What about in a disaster year, the government subsidy policy for suppliers and retailers who are in the dominant position in the supply chain? The future research can design the optimal government subsidy policy in disaster year and normal year according to the barging power of retailers and suppliers in supply chain and the retailers' cooperation preference.

\section{Acknowledgements}

We would like to express our gratitude to all those who has helped us during the writing of this paper. The authors will take full responsibility for all the faults in the paper.

\section{Fundings}

This research was funded by National Social Science Fund of China (No. 21BJY192), Beijing Social Science Fund (No.20JCB003), Beijing Philosophy and Socail Science Capital Circulation Industry Research Center (No.JD-YB-2021-050) and National Social Science Fund of China (No. BDA200079) .

\section{Conflicts of interest}

The authors declare no conflict of interest.

\section{References}

Bellantuono, N., I. Giannoccaro, P. Pontrandolfo and C.S. Tang. 2006. The implications of joint adoption of revenue-sharing and advance booking discount programs. International Journal of Production Economics 121(2): 383-394.

Cachon, G.P. 2003. Supply chain coordination with contracts. In: S.C. Graves and A.G. de Kok (eds.) Handbooks in operations research \& management science. Vol. 11. Supply chain management: design, coordination and operation. Elsevier, New York, NY, USA, pp. 227-339. https://doi.org/10.1016/ S0927-0507(03)11006-7

Cachon, G.P. and M.A. Lariviere. 2001a. Contacting to assure supply: how to share demand forecast in a supply chain. Management Science 47(5): 629-646. 
Cachon, G.P. and M.A. Lariviere. 2001b. Turning the supply chain into a revenue chain. Harvard Business Review 79(3): 20-21.

Cachon, G.P. and M.A. Lariviere. 2005. Supply chain coordination with revenue-sharing contracts: strengths and limitations. Management Science 51(1): 30-44.

Chauhan, S.S. and J.M. Proth. 2004. Analysis of a supply chain partnership with revenue-sharing. International Journal of Production Economies 9: 44-51.

Dan, B. and J. Chen. 2008. Supply chain coordination of fresh agricultural products based on value loss. Chinese Journal of Management Science 16(5): 42-49.

Dan, B., H.Y. Fu and G.Y., Xu. 2013. Supply chain coordination of agricultural products considering the influence of weather and effort level on yield and quality. Systems Engineering Theory and Practice 33(9): 2229-2238.

Dan, B., H.Y. Fu and G.Y. Xu. 2014. Supply chain coordination of agricultural products with weather affecting output under risk aversion. Journal of Systems Engineering 29(3): 362-370.

Ding, J.P. and Y.J. Gao. 2015. Research on the development of nongchao docking. World Agriculture 2: 176-179.

General Administration of Customs of the People's Republic of China. 2019. General Administration of Customs yearbook. China Statistics Press, Beijing, China.

Hobbs, J.E. and L.M. Young. 1999. Increasing vertical linkages in agri-food supply chains: a conceptual model and some preliminary evidence. Canadian Journal of Agricultural Economics - Revue canadienne d'agroeconomie 47(4): 478.

Hu, D.H. and W.M. Yang. 2010. 'The connection between rural and supermarket': significance and challenges. Management and Administration on Rural Cooperative 17: 17-19.

Jeuland, A.P. and S.M. Shugan. 1983. Managing channel profits. Marketing Science 2: 239-272.

Liang, X. and Z. Fang. 2016. Research on cost-sharing contract of supply revenue-sharing based on retailer promotion. Commercial Research 3(467): 171-178.

Liu, X.F. 2011. Analysis on the composition and intermediary effect of farmers' psychological contract under the model of 'the connection between farmers and supermarkets'. Finance and Trade Economics 2: 69-73.

Luo, M. and Y. Chen. 2015. Study on agricultural produce quality and safety control based on farm-supermarket docking. Logistics Technology 34(22): 61-63.

Mighell, R.L. and L.A. Jones. 1963. Vertical coordination in agriculture. Economic Research Service, USDA, Washington, DC, USA.

National Bureau of Statistics of the People's Republic of China. 2019. China statistical yearbook. China Statistics Press, Beijing, China.

Ren, W.H., K. Fan and X. Zhang. 2013. Research on 'rural and supermarket docking' in China. Eastern Forum 2: 119-125.

Statistical Bureau of Xuwen County, Zhanjiang City. 2019. Xuwen yearbook. Guangdong Peoples Publishing House, Guangdong, China.

Stokke, H.E. 2009. Multinational supermarket chains in developing countries: does local agriculture benefit? Agricultural Economics 40(6): 645-656.

Tang, W.Q., L. Zou and S. Lu. 2014. Incentive decision on safety investment of supply chain of agricultural products in 'agricultural super-docking'. Journal of Applied Mathematic, Article ID: 836342.

Wang, Y.Z., L. Jiang and Z.J. Shen. 2004. Channel performance under consignment contract with revenuesharing. Management Science 50(1): 34-37.

Whitin, T.M. and G. Hadley. 1963. Analysis of inventory systems. Prentice-Hall, Englewood Cliffs, NJ, USA. 
